\title{
Use of Standardized Test to Develop Literacy Levels of Students in Primary Schools
}

\author{
Horatio Morgan* \\ Research Analyst, Supreme Court of Jamaica, Kingston, Jamaica \\ *Corresponding author: horatio.morgan@yahoo.com
}

Received August 19, 2014; Revised August 25, 2014; Accepted September 10, 2014

\begin{abstract}
The purpose of this study is to investigate the effect of the Grade Four Literacy Test (G4LT) in Jamaica as a preparatory agent for improved performances in the literacy levels of students who complete the standardized Grade Six Achievement Test (GSAT). This research was based on the use of quantitative analysis and variable correlations. Data was collected from a secondary source on performance rates of students who completed the G4LT and the GSAT in the areas of Language Arts and Communication Task from 2003 to 2013. In-addition, data was obtained from the Devinfo Edustatjamaica Database of the Planning Institute of Jamaica (PIOJ) and reviewed using the Statistical Package for the Social Sciences and Micro-Soft Word Excel. The results indicated that indeed there exist a relationship between the performance levels on the G4LT and the GSAT Examinations. It also showed that in both examinations, relative increases have taken place in the national averages of the students.
\end{abstract}

Keywords: literacy, standardization, examination, correlation, trend, effect, analysis

Cite This Article: Horatio Morgan, "Use of Standardized Test to Develop Literacy Levels of Students in Primary Schools." American Journal of Educational Research, vol. 2, no. 9 (2014): 811-816. doi: 10.12691/education-2-9-16.

\section{Introduction}

The Ministry of Education has in the last five years, adopted as its mandate the statement "Every Child Can Learn, Every Child Must Learn” to articulate its position on child development. However, this mental state was long engraved in the Jamaican society's psyche. Thus, in 1999 the government of the day attempted to support this long held vision by introducing the G4LT. Henceforth, this programme was launched with an ambitious heart to provide formative assessment of student's progress at the grade four level through the sitting of the summative Grade Four Literacy Test (G4LT). This examination would serve to identify weak areas in students and interventions made before those students sit the final Primary school examination; which was the Grade Six Achievement Test (GSAT).

It may be argued that the verdict is still out on how significant of an influence the G4LT has had on improvements in the literacy level of Jamaican children. However, it is acknowledged that this was a very good step to at least ascertain the students' levels of literacy; as the GSAT results could be used as valuable data in policy making. In-addition, the progress in certain subject areas could be tracked with an eye to improve students' overall output. This was always being done, but the veracity in which it is currently being pursued highlights its importance to nation building and the $21^{\text {st }}$ century student. Hence, the Honourable Minister Ronald Thwaites in The Gleaner said that "this year's results have shown improvements in the national average in all subject areas; which would presume that schools would receive students who are better prepared for secondary education". [6].

This was highlighted by a fairly recent study that gave an accurate description of the G4LT by stating that the literacy test was now to become the focal point of primary education in regulating the flow of primary school students to secondary school through assessment of students' literacy competence as assessed by the G4LT. The test was to be nationalized, meaning that it would be administered by the Education Ministry's staff. Students who failed the G4LT had three to four other opportunities to retake the test. The summer school option was replaced by having the schools create programs to assist their struggling readers. Schools that performed poorly (below the national literacy average) would have the additional support of literacy specialists sent out by the Education ministry. All students would still be promoted to grades five and six regardless of whether they passed the literacy test or not since at each level there would be supplemental sittings of the literacy test. However, only those students who were "certified as literate" would be allowed to sit the Grade Six Achievement Test in March. That is to say, struggling readers who failed to pass any of the three or four sittings of the G4LT would not be allowed to sit GSAT, in the major secondary school placement examination. [10].

\subsection{Statement of the Problem}

Given the importance of education to nation building and to the development of the $21^{\text {st }}$ century citizen, it has 
become vital to institute actions that would redown to the development of holistic students capable of clearly expressing themselves in any forum and not just students who are able to just read and write. Hence, this study seeks to investigate the effect of the G4LT on the outcome of literacy levels at the GSAT level using the Language Arts and Communication Task as indicators/proxies from 2003 to 2013.

Through research a detailed situational analysis of the Jamaican education system was provided. Among the findings, the report concluded that a significant number of primary-aged students had not acquired the minimum acceptable literacy and numeracy competencies [15]. Thus, this deficiency has in turn resulted in students being illequipped to engage in secondary-level education. Following this report, it is thought that some evaluation must be put in place to ascertain if the G4LT is accomplishing what it was meant to do. In-addition, there have been a few reports in the media which showed the Jamaican public's sentiments on the examination [14].

In Ref [14], the article questioned the competence level of children who were said to have been highly successful in the examination. Therefore, it is suggested that if proper evaluations were being conducted and reported, then the public would have been better able to draw more accurate conclusions about the effect of the programme on the literacy levels of students in preparation for GSAT. Furthermore, it would show if increasing national pass rate in the examination has a relationship with the pass rate of the GSAT in the area of Language Arts and Communication Task

For the purposes of this study, the following research questions will be asked. These questions should serve as a guide to conducting the research.

- Are there any changes overtime in the pass rate of students sitting the G4LT and GSAT examinations from 2004 - 2014 in the areas of Language Arts and Communication Task?

- Is there synonymous change overtime in the mastery levels in first time sitting students of the G4LT?

- Does some relationship exist between the results of the G4LT and the identified areas of the GSAT Examination?.

\subsection{Literature Review}

The GSAT is Jamaica's premier standardized Primary School Examination. Often times, it is one of a few determinants that has a significant effect on the outcome of educational attainment of a child. As important as this examination is to a child's future, its results/outcomes are influenced by the G4LT. Ref. [10] stated that all students would still be promoted to grades five and six regardless of whether they passed the literacy test or not since at each level there would be supplemental sittings of the literacy test. However, only those students who were "certified as literate" would be allowed to sit the Grade Six Achievement Test in March. That is to say, struggling readers who failed to pass any of the three or four sittings of the G4LT would not be allowed to sit GSAT, the major secondary school placement exam. Instead students who failed to pass the literacy test by grade six would be placed in the Alternate Secondary Education Programme (ASEP) which is now being implemented. The author used this study to explore the origins or the G4LT and how it evolved from a class room exercise into a full blown standardized national examination. She gave credence to the examination's history and context in relation to Jamaica's national development. For this study, the information regarding the importance, history and relationship of the G4LT to the GSAT was highlighted. The following were literatures used to gain insights knowledge into the area;

Gorard, Rees and Salisbury (2001) investigated the patterns of differential attainment of boys and girls in schools. They found that there are few significant differences in Mathematics and the Sciences; which is in the majority of core subjects. Otherwise, the gap in attainment between boys and girls rises with every grade or level in an assessment, leading to the conclusion that the problem, if indeed it is a problem, is one mainly facing mid-to-high-attainers. [5]. Proportionately, more girls are attaining high grades and more boys are attaining middle grades than expected. This study showed that although girls are performing above average they also perform poorly outside the high attainer group; therefore, rendering their average lower than of the boy's because of the outliers present in the data. However, the boys averages were centred in the middle; therefore, giving a higher median value.

Allred (1984) in his research on Standardized Spelling test and Written Spelling Test sought to answers the following questions;

1. What is the correlation between student standardized test scores and written spelling test scores for students from high, medium and low achieving schools in six (6) geographic areas in the United States from grades one (1) to six (6) for:

a. each grade?

b. each sex by grade?

2. Are there significant differences in the raw scores obtained by students when analyzing the differences between standardized spelling achievement test scores and written test results for:

a. each grade?

b. each sex by grade?

The results showed that high significant correlations were found for each grade and each sex by grade at all levels. [1]. This research is similar to the current study because it looked at the difference between two (2) standardized tests and the relationship between both the boys and girls who sit these examinations.

White (2007) sought to address the question: Are girls better readers than boys through the use of Ontario's 2002 large-scale administration of the Ontario's Secondary School Literacy Test (OSSLT). It was concluded that the notion of under-achievement of boys in the area of reading achievement has been greatly overstated. In-addition, the author opined that further studies supporting this finding maybe required. [16] This research was important because it highlighted the relationship of the results of the boys when compared to the girls in both the GSAT and G4LT.

Allred (1990), in Gender Differences in Spelling Achievement in Grades 1 Through 6, compared the performances of boys and girls on standardized proof reading and written spellings tests for students from high, medium and low achieving school in six geographic areas of the United States. It was found that girls scored 
significantly higher, resulting in the conclusion that girls spell better than boys at all levels. [2]. This study was important because it highlighted a significant area of literacy and shows which sex handles it better under controlled conditions.

Mertler (2007) explored various aspects of standardized testing; including its history, characteristics, development and types. He further described standardized testing as any test that is administered, scored and interpreted in a standard consistent manner. It does not matter if the test is administered to students in Ohio or Oregan, Maine or Michigan, Connecticut or California; there is a standard set of procedures for administering the test to those students. It is standard because it remains constant no matter time or place within a country [11].

Ortlieb and Cheek (2013) highlighted best practices of literacy instruction for students who have difficulties in reading. From components of effective pedagogy to instruction for specific populations, this text offers an array of expert perspectives on how to engage, scaffold, and prepare students to meet the multimodal demands of schools today. The authors further promoted the notion that with thoughtful literacy and purposeful approaches to reading instruction, all children have the ability to improve their reading proficiencies. Core literacy instruction targeting comprehension, fluency, vocabulary, and writing development among others is of particular focus while supplementary discussions of factors such as native language, diversity, inclusion, and learning disabilities fully characterize issues related to struggling readers for which evidence-based approaches are presented to foster lasting success [12]. It conveys a current portrayal of issues and trends of school-based literacy practices appropriate for novice and experienced educators and researchers alike.

Kim, Jennifer, Robert, and Ardice (2010) posited a research that examine the causal effects of READ 180, as a mixed-methods literacy intervention, on measures of word reading efficiency, reading comprehension and vocabulary, and oral reading fluency and (2) to examine whether print exposure among children in the experimental condition explained variance in posttest reading scores. This was done for two (2) distinct sets of children.

The results showed that there was no significant difference between children in READ 180 and the district after-school program on norm-referenced measures of word reading efficiency, reading comprehension, and vocabulary. Although READ 180 had a positive impact on oral reading fluency and attendance, these effects were restricted to children in Grade 4. Results indicated that neither the use of the Success Maker nor READ 180 intervention program made a significant impact on NJASK6 scores. However, students in the READ 1800 intervention showed significantly higher SRI Lexile scores than their comparison group counterparts. [8] Significantly, this dissertation identifies with the needs of the current study because it showed that with any intervention, this may improve student literacy output and therefore, if remedial action is taken at the grade four levels, then this would impact the output at the GSAT level.

Kennedy (2003) reviewed the nature of standardized tests preparation for schools using, the following; a model and adopting a systemic approach to improvement and change, aligning the educational process with desired outcomes, aligning the educational process with inputs, creating positive change and also undertook a case study of an elementary school / Leslie Jones-Hamilton to test his theory. It was found that standardized tests have the potential to improve schools, are associated with high stakes accountability programmes and also have the potential to do a great deal of damage to the teaching and learning process. [7].This literature study illustrated how standardized examination educational model could be used to improve student output

Geske and Ozola (2009) investigated the hypothesis that boys and girls are differently affected by the same factors,. In-addition, they sought to find out which factors have the most influence on boys reading achievements. It was found that school environment has greater impact on boys reading literacy. Furthermore, it was concluded that more investigations are needed on factors influencing literacy among the genders. [4]. This literature gave insights into the behaviours of boys to boys and boys to girls attitudes, when face with literacy training.

Kohn (2000) posited an argument that standardized tests are, "not like the weather, something to which we must resign ourselves. They are not a force of nature but a force of politics- and political decision and be questioned, challenged and ultimately reversed'. Among other things he stated that high scores often signify relatively superficial thinking, many of the leading test were not intended to measure teaching or learning and that far more meaningful measures off student learning or school quality are available. [9]. This book gave an outline of the disadvantages of using standardized test and served as a good balance for the research, by highlighting the weaknesses of using standardized tests.

\section{Materials and Methods}

In an effort to measure the effect of the Grade Four Literacy Test (G4LT) as a preparatory agent for improved performances in the literacy levels of students who complete the Standardized Grade Six Achievement Test (GSAT) in Jamaica; background information was first sought through literature reviews and consultations with resource persons on the study. Contact was also made with the Planning Institute of Jamaica (PIOJ) to ascertain whether data existed on this area of research. Hence, the following data was received as shown in tables 1-3

Table 1. Shows Jamaica, Proportion of students achieving full mastery in the Grade 4 Literacy Test - Percent

\begin{tabular}{|c|c|c|c|}
\hline Year & Total-G4LT & Male-G4LT & Female-G4LT \\
\hline 2003 & 57.7 & 70.4 & 45.7 \\
\hline 2004 & 57 & 69.3 & 45.2 \\
\hline 2005 & 63.9 & 76.4 & 51.9 \\
\hline 2006 & 64.8 & 77.2 & 52.9 \\
\hline 2007 & 63.5 & 76.6 & 53.2 \\
\hline 2008 & 71.7 & 82.9 & 61 \\
\hline 2009 & 70.1 & 81.3 & 59.1 \\
\hline 2010 & 66.9 & 77.5 & 56.4 \\
\hline 2011 & 71.4 & 81.6 & 61.5 \\
\hline 2012 & 73.7 & 83.2 & 64.6 \\
\hline 2013 & 76.4 & 85.2 & 67.9 \\
\hline Table above was taken from & the Devinfo \\
Edustatjamaica & & Database:
\end{tabular}


http://www.devinfo.org/edustatjamaica/stock/shared/dv/Pi votData_2014_7_24_635418125856461015.htm

Table 2. Shows Jamaica, Grade Six Achievement Test (GSAT) mean score - Communication Task - Score, Mean Raw Scores and Percent Mean

\begin{tabular}{|c|c|c|c|}
\hline Year & Total GSAT- CT & Male GSAT-CT & Female GSAT-CT \\
\hline 2003 & $8(66.67 \%)$ & $9(75.00 \%)$ & $7(58.33 \%)$ \\
\hline 2004 & $6(50.00 \%)$ & $7(58.33 \%)$ & $6(50.00 \%)$ \\
\hline 2005 & $5(41.67 \%)$ & $6(50.00 \%)$ & $4(33.33 \%)$ \\
\hline 2006 & $6(50.00 \%)$ & $7(58.33 \%)$ & $5(41.67 \%)$ \\
\hline 2007 & $8(66.67 \%)$ & $9(75.00 \%)$ & $7(58.33 \%)$ \\
\hline 2008 & $7(58.33 \%)$ & $8(66.67 \%)$ & $6(50.00 \%)$ \\
\hline 2009 & $7(58.33 \%)$ & $8(66.67 \%)$ & $7(58.33 \%)$ \\
\hline 2010 & $8(66.67 \%)$ & $9(75.00 \%)$ & $7(58.33 \%)$ \\
\hline 2011 & $8(66.67 \%)$ & $9(75.00 \%)$ & $8(66.67 \%)$ \\
\hline 2012 & $9(75.00 \%)$ & $9(75.00 \%)$ & $9(75.00 \%)$ \\
\hline 2013 & $9(75.00 \%)$ & $9(75.00 \%)$ & $8(66.67 \%)$ \\
\hline
\end{tabular}

Taken above was taken from the Devinfo Edustatjamaica Database: http://www.devinfo.org/edustatjamaica/stock/shared/dv/Pi votData_2014_7_24_635418124980665787.htm

Table 3. Shows Jamaica, Grade Six Achievement Test (GSAT) mean score - Language Arts - Score

\begin{tabular}{|c|c|c|c|}
\hline Year & Total GSAT- LA & Male GSAT-LA & Female GSAT-LA \\
\hline 2003 & 52 & 57 & 47 \\
\hline 2004 & 48 & 52 & 45 \\
\hline 2005 & 54 & 59 & 48 \\
\hline 2006 & 54 & 59 & 49 \\
\hline 2007 & 48 & 53 & 44 \\
\hline 2008 & 53 & 58 & 48 \\
\hline 2009 & 57 & 62 & 51 \\
\hline 2010 & 58 & 63 & 53 \\
\hline 2011 & 58 & 61 & 54 \\
\hline 2012 & 60 & 63 & 56 \\
\hline 2013 & 63 & 67 & 59 \\
\hline
\end{tabular}

Table above was taken from the Devinfo Edustatjamaica Database: http://www.devinfo.org/edustatjamaica/stock/shared/dv/Pi votData_2014_7_24_635418124260872559.htm

The data above was secondary and collected from the PIOJ's Devinfo edustatjamaica database. The PIOJ is Jamaica's premier National Planning Agency that is "committed to leading the process of policy formulation on economic and social issues and external co-operation management to achieve sustainable development for the people of JAMAICA” [13].

It was established that based on the data and purpose of the study, it would be quantitative based, focusing on historical data (averages) pertaining to the results of students who completed G4LT and the GSAT (CT and LA) examinations from 2003 to 2013. The years 2003 to 2013 was particularly chosen for the following reasons;

- the availability of accurate and reliable data from the country's national source

- the thought that any major problems that existed when the G4LT commenced in 1999 would have been addresses within the three years prior to this study

The approach to the study incorporated quantitative analysis of the results of both examinations and also variable correlations among the results obtained, to establish if there existed any relationship and trends among the results of examinations.

Arising out of the needs of this study, the data was reviewed using the Statistical Package for the Social Sciences (SPSS) to ascertain if correlation existed and the strength of those relationships. In-addition, Micro-Soft Word Excel was used to analyze the historical trends of the examination results. In-addition, the GSAT CT data was repackaged to include percentages for representation and analysis purposes.

\section{Results and Discussions}

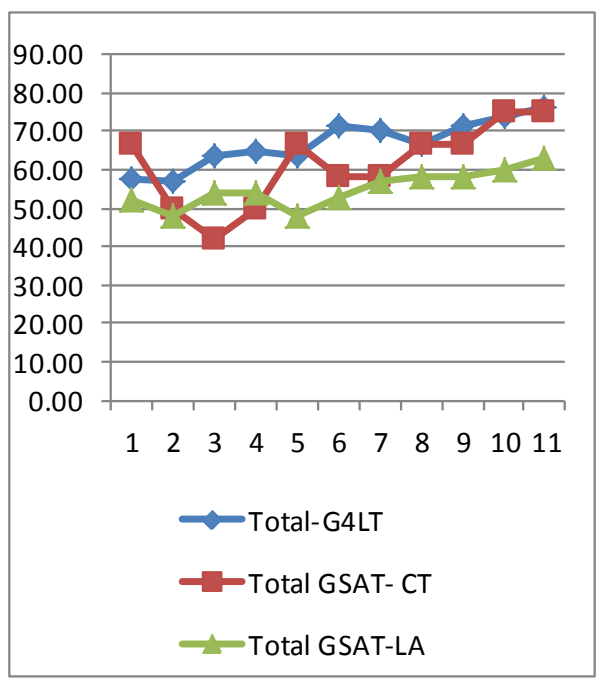

Figure 1. Shows total result trends over 11 years for the G4LT, GSAT CT/ LA examinations

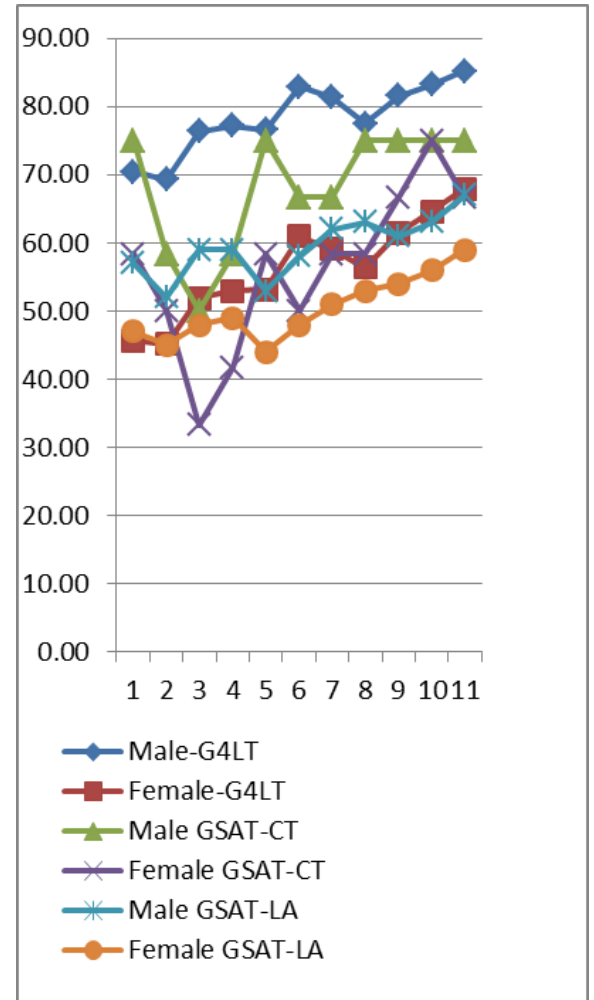

Figure 2. Show result trends over 11 years for the G4LT, males and females who completed the GSAT CT / LA examinations

Reference is made to the Figure 1., over time it was seen that although the average results for the G4LT fluctuated, its fluctuation took place in an upward manner. This showed that general improvement in student's output was taking place. The GSAT Communications Task (CT) results also fluctuated on a wider plain over time than the 
G4LT and also showed marked improvements over the eleven year period. However, the GSAT Language Arts (LA) results were generally lower than both the G4LT and the GSAT CT. This is of major concern and should be quickly addressed because this component of the standardized test gives a good indication of the literary levels of students moving from Primary Schools to High Schools in Jamaica.

As shown in Figure 2. below, there is a general fluctuation in the results of both the male and female students who complete the GSAT (CT and LA) examinations. It was remarkable to notice that boys consistently outperformed girls in the GSAT examinations (CT and LA) and that the results trended upwards; indicating improvements in the literacy levels of children who complete both the G4LT and GSAT examinations. [5] and [16]. Significantly, this finding contradicts the findings in Ref [2].

Based on Figure 1 and Figure 2, which were previously mentioned, it could be seen that a relationship does exist between results for both examinations as a whole and individually for each sex [1]. However, the strengthens of those relationships may be seen in the tables below;

Table 4. Shows the significance of the relationships among the results for the G4LT and the GSAT CT / LA examination results

\begin{tabular}{|c|c|c|c|c|}
\hline & & TOTAL GFLT & TOTAL GSAT CT & TOTAL GSAT LA \\
\hline \multirow{3}{*}{ TOTAL G4LT } & Pearson Correlation & 1 & .519 & $.825 * *$ \\
\hline & Sig. (2-tailed) & & .102 & .002 \\
\hline & $\mathrm{N}$ & 11 & 11 & 11 \\
\hline \multirow{3}{*}{ TOTAL GSAT CT } & Pearson Correlation & .519 & 1 & .526 \\
\hline & Sig. (2-tailed) & .102 & & .097 \\
\hline & $\mathrm{N}$ & 11 & 11 & 11 \\
\hline \multirow{3}{*}{ TOTAL GSAT LA } & Pearson Correlation & $.825 * *$ & .526 & 1 \\
\hline & Sig. (2-tailed) & .002 & .097 & \\
\hline & $\mathrm{N}$ & 11 & 11 & 11 \\
\hline
\end{tabular}

Reference is made to Table 4 above, which shows that there exist a strong correlation between the GFLT and the GSAT LA results $(0.825)$ at the $1 \%$ Confidence Level.
This is saying that the G4LT does have an influence on the results of the GSAT Language Arts Examination. [1].

Table 5. Shows the significance of the relationships among the results for the G4LT and the GSAT CT / LA examination results (male and female)

\begin{tabular}{|c|c|c|c|c|c|c|}
\hline & & TOTAL G4LT & MALE GSAT CT & FEMALE GSAT CT & MALE GSAT LA & FEMALE GSAT LA \\
\hline \multirow{3}{*}{ TOTAL G4LT } & & 1 & .382 & .516 & $.803^{* *}$ & $.821 * *$ \\
\hline & & & .246 & .104 & .003 & .002 \\
\hline & & 11 & 11 & 11 & 11 & 11 \\
\hline \multirow{3}{*}{ MALE GSAT CT } & & .382 & 1 & $.884 * *$ & .336 & .440 \\
\hline & & .246 & & .000 & .312 & .176 \\
\hline & & 11 & 11 & 11 & 11 & 11 \\
\hline \multirow{3}{*}{ FEMALE GSAT CT } & & .516 & $.884 * *$ & 1 & .434 & $.616^{*}$ \\
\hline & & .104 & .000 & & .182 & .044 \\
\hline & & 11 & 11 & 11 & 11 & 11 \\
\hline \multirow{3}{*}{ MALE GSAT LA } & & $.803 * *$ & .336 & .434 & 1 & $.942 * *$ \\
\hline & & .003 & .312 & .182 & & .000 \\
\hline & & 11 & 11 & 11 & 11 & 11 \\
\hline \multirow{3}{*}{ FEMALE GSAT LA } & & $.821 * *$ & .440 & $.616^{*}$ & $.942 * *$ & 1 \\
\hline & & .002 & .176 & .044 & .000 & \\
\hline & $\mathrm{N}$ & 11 & 11 & 11 & 11 & 11 \\
\hline
\end{tabular}

Reference is made to the Table 5 above, at the $1 \%$ Confidence level, the G4LT does have an influence on the results of both the boy's and girl's results in the GSAT LA Examinations (0.83 and 0.821, respectively); which was consistent with the results of the relationship among the variables seen in Table 1. [16].

It was found that individual relationships among boys and girls sitting the examination had a profound impact on the outcome of the results of those examinations. This showed that parents must seek to develop their children as sociable individuals who would positively contribute to their fellow students' development. This is also important because it showed that children could be buffers for each other under examination pressure conditions [16].

The data showed that the female students had less influence on male students performance (0.942 at the $1 \%$ confidence level)); while females had more influence on other females $(0.616$ at the $5 \%$ confidence level). Contrastingly, the influence of male to other male on performance in the examination was not significant.
However, the relationship experienced between male to female students were significant $(0.942$ at the $1 \%$ confidence level). [4]. Hence, further investigations are needed to identify the specific conditions and factors that influence each gender's behaviour.

\section{Conclusions}

The G4LT is thought to be a great initiative to improve Primary Education in Jamaica. It was through this initiative that the government sought to intervene and raise the literacy outputs of students sitting the GSAT examination. Hence, the results of the G4LT would be used to identify and enable school administrators to implement remedial work in failing children before they leave the primary school level; which would result in them being aptly prepared for High School. It is seen where the Ministry of Education occasionally publishes summary data on both examinations (G4LT and GSAT); however, 
no comprehensive literature review has been presented to the country to support the claim that in-fact the G4LT is actually influencing better examination results in the GSAT. Hence, the purpose of this study is to shed some light on the impact the G4LT has on the outcome of the GSAT examination.

\subsection{Limitations to the Study}

For this study, the data used was secondary and collected for reporting purposes by another user. Therefore, it is acknowledges that it may contain errors. In-addition, no total figure of examination participants was stated for the data collected; only averages were given. This could have had a significant effect on the averages, because the larger the denominator in an equation, the smaller the results; which might be the case with the girls averages in the research.

Reference is further made to the abovementioned point, because there exist an all-girls Primary School in Jamaica and this could possibly skew the reported results of the averages from the primary data source. One such school exist in Kingston, the "St. Georges’ Girls Primary School”.

\section{Acknowledgements}

It is with great pleasure that I thank Professors Helen Abadiano, Olusegun Sogunro and Carol Carter-Lowery from the Department of Educational Leadership at the Central Connecticut State University for inspiring me to produce this important research in the evaluation of the Jamaican Primary School system.

\section{Statement of Competing Interest}

This author has no competing interests.

\section{List of Abbreviations}

G4LT - Grade Four Literacy Test

GSAT - Grade Six Achievement Test

PIOJ - Planning Institute of Jamaica

GSAT CT - Grade Six Achievement Test Communication Task

GSAT LA - Grade Six Achievement Test Language Arts
ASEP - Alternate Secondary Education Programme

NCLB - No Child Left Behind

\section{References}

[1] Allred, R. A., Comparison of proofreading-type standardized spelling tests and written spelling test scores. The Journal of Educational Research, 77.5: 298-303, 1984.

[2] Allred, R. A., Gender differences in spelling achievements in grades 1 through 6. The Journal of Educational Research, 83.4: 187-193, 1990.

[3] James, P, Test better, teach better: The instructional role of assessment (pp. v-vi). Alexandria, Va: Association for Supervision and Curriculum Development, 2003.

[4] Geske, A., and Ozola, A., Different influence of contextual educational factors on boys' and girls' reading achievements. USChina Education Review, 6.4: 38-44, 2009.

[5] Gorard, S., Rees, G., and Salisbury, J., Investigating the patterns of differential attainment of boys and girls at school. The Journal of Educational Research, 27. 2: 125-139, 2001.

[6] Grange, M, GSAT results released, The Gleaner, June 2012.

[7] Kennedy, E, Raising test scores for all students: An administrator's guide to improving standardized test performances: N.p. Corwin, 2003.

[8] Kim, James S., Jennifer F. Sampson, Robert Fitzgerald, and Ardice Hartry, "A randomized experiment of a mixed-methods literacy intervention for struggling readers in grades 4-6: Effects on word reading efficiency, reading comprehension and vocabulary, and oral reading fluency," Reading and writing 23.9: 1109-11029, 2010.

[9] Kohn, A, The case against standardized testing: Raising the scores, ruining the schools. Portsmounth, NH: Heinemann, 2000.

[10] Lewis, Y. E. (2010). Literacy in elementary school in Jamaica: The case of the grade four literacy test." University of Iowa, 2010. [Online]. Available: http://ir.uiowa.edu/etd/698. [Accessed Jul. 19, 2014]

[11] Mertler, C. A, Interpreting standardized test scores: Strategies for data-driven instructional decision making (p. 3). Los Angeles: Sage Publications, 2007.

[12] Ortlieb, E. and Cheek, E. H. (Eds.). School-based interventions for struggling readers, K-8 (Vol. 3). N. p.: Bingley: Emerald, 2013.

[13] Planning Institute of Jamaica (2008-12). In Planning Institute of Jamaica: An Agency of the Ministry of Finance and Planning. 2008. [Online]. Available: http://www.pioj.gov.jm/AboutUs/MissionVision/tabid/71/Default. aspx. [Accessed Aug. 12, 014]

[14] Roxborough, P, 4 literacy test said not effective, Jamaica Observer, 2002.

[15] Taskforce on Educational Reform Jamaica (2004). Retrieved July 19, 2014, from Available, 2004. [Online]. Available: http://planipolis.iiep.unesco.org/upload/Jamaica/Jamaica_2004_Ta sk_Force_Ed_Reform_final_report.pdf. [Accessed Jul. 19, 2014]

[16] White, B., Are girls better readers than boys? Which Boys? Which Boys? Canadian Journal of Education, 30. 2: 554-581, 2007. 